\title{
Vitamin D and Other Risk Factors among Stroke Patients Pokharel BR, ${ }^{1}$ Kharel G, ${ }^{2}$ Thapa $L J,{ }^{2}$ Rana PVS ${ }^{2}$
}

${ }^{1}$ Department of Medicine

Dhulikhel Hospital, Kathmandu University Hospital

Dhulikhel, Kavre, Nepal

${ }^{2}$ Department of Neurology

College of Medical Science

Bharatpur, Chitwan, Nepal

\section{Corresponding Author}

Babu Ram Pokharel

\section{Department of Medicine}

Dhulikhel Hospital, Kathmandu University Hospital

Dhulikhel, Kavre, Nepal

E-mail: drbrpokh@gmail.com

\section{Citation}

Pokharel BR, Kharel G, Thapa LJ, Rana PVS. Vitamin $\mathrm{D}$ and Other Risk Factors among Stroke Patients. Kathmandu Univ Med J 2015;49(1):71-3.

\section{ABSTRACT}

\section{Background}

Stroke is common neurological problems in Nepal. The common risk factors for stroke are age, hypertension, diabetes, dyslipidemia and atrial fibrillation. Vitamin D is an emerging risk factors for cardio-cerebrovascular disease.

\section{Objective}

This study is to find out Vitamin D and risk factors in stroke patient in Nepalese population.

\section{Method}

We reviewed the record of 281 stroke patients, admitted to Neurology ward of College of Medical Sciences, Bharatpur, Nepal from $1^{\text {st }}$ January to $31^{\text {st }}$ December 2013 . The records were analyzed on the basis of age, sex, hypertension (HTN), body mass index (BMI), smoking habits, hemoglobin( $\mathrm{Hb}$ ), diabetes mellitus(DM), Lipid profile, Atrial fibrillation(AF) and vascular territory with clinical and radiological evidences. The vitamin $D$ analysis was done all stroke patients.

\section{Result}

Total patient were 281, with male 161 and age range from 18 - 87. Ischemic stroke was noted in $86.8 \%$ and hemorrhagic stroke was noted in $13.2 \%$ of patients. Middle cerebral artery (MCA) ischemia was noted in $51.5 \%$ of patients and anterior cerebral artery (ACA) ischemia was noted in $3 \%$ of patients. Multiple infarcts were noted in $12.90 \%$ of patients. About half of them were smoker, hypertension $47.40 \%$, Diabetes mellitus $24.20 \%$ and $14.1 \%$ had atrial fibrillation. 174 (61.92\%) of the stroke had less than sufficient Vitamin D.

\section{Conclusion}

The common risk factors for stroke patients like smoking, hypertension, diabetes mellitus and atrial fibrillations are present in Nepalese population. The level of vitamin $D$ was also low in stroke patients.

\section{KEY WORDS}

Stroke, vitamin D 


\section{INTRODUCTION}

Stroke is one of the leading causes of death and disability worldwide and also increasing trend in low and middle income countries like Nepal. According to WHO global health estimates, 6.7 millions of deaths were due to strokes. ${ }^{1}$ The rates of major cardiovascular events like stroke are higher in low and middle-income countries (LMIC) than high income countries however risk factor burden is lower in LMICs. ${ }^{2}$

There are various modifiable and non-modifiable risk factors for stroke. Established risk factors for cardiocerebrovascular diseases - smoking, hypertension, diabetes mellitus, dyslipidemia, obesity, physical activity, age are increasing in LMICs which correlates with morbidity and mortality. Recent studies have shown that there is a role of Vitamin D in stroke events.

Several mechanisms have been proposed on how vitamin $D$ could be involved in blood pressure regulation and the pathophysiology of arterial hypertension, which is a major risk factor for stroke. Vitamin $D$ effects on the renin angiotensin aldosterone system (RAAS) have been extensively investigated by experimental studies. The different stages of atherogenic process evolves, starting from inflammatory endothelial activation/dysfunction and resulting in plaque vulnerability and rupture. ${ }^{3}$

\section{METHODS}

We reviewed the record of 281 stroke patients, admitted in College of Medical Sciences, Bharatpur, Nepal from $1^{\text {st }}$ January to $31^{\text {st }}$ December 2013. They were investigated with blood tests, imaging and managed medically.

The records were analyzed for risk factors - age, sex, hypertension (HTN), body mass index (BMI), smoking, hemoglobin $(\mathrm{Hb})$, diabetes mellitus (DM), lipid profile, atrial fibrillation (AF), serum vitamin D. Stroke subtype and vascular territory were analyzed on the basis of CT scan imaging evidences.

The Data were analyzed by using the SPSS version 20.

\section{RESULTS}

Among 281 stroke patients, 161 were male, age range from 18 to 87 years.

Table 1. Baseline characteristics

\begin{tabular}{ll}
\hline Parameters & Stroke patients $(\mathbf{n = 2 8 1})$ \\
\hline Age range years & $18-87$ \\
\hline Men & $161(57 \%)$ \\
\hline SBP & $138 \pm 27.62 \mathrm{mmHg}$ \\
\hline DBP & $86.5 \pm 18 \mathrm{mmHg}$ \\
\hline BMI & $26.32 \pm 4.54 \mathrm{~kg} / \mathrm{cm}^{2}$ \\
Hb & $13.02 \pm 2.59 \mathrm{gm} / \mathrm{dl}$ \\
\hline
\end{tabular}

Table 2. Common risk factors of stroke patients

\begin{tabular}{ll|}
\hline Risk factors & Number of Patients \\
\hline Smoking & $149(52.5 \%)$ \\
\hline Diabetes Mellitus & $67(24.2 \%)$ \\
\hline Hypertension & $132(47.4 \%)$ \\
\hline Triglycerides $>150$ & $87(31.4 \%)$ \\
\hline High Density Lipoprotein $<40$ & $126(45.5 \%)$ \\
\hline Atrial fibrillation & $39(14.1 \%)$ \\
\hline
\end{tabular}

Smoking was present in $52.5 \%$ while Diabetes mellitus in $24.2 \%$, hypertension $47.2 \%$, high density lipoprotein less than 40 in $45.5 \%$ respectively.

Table 3. Level of Vitamin D

\begin{tabular}{|ll|}
\hline Vitamin D & No of patients \\
\hline $0-10$ (deficient) & $12(4.27 \%)$ \\
\hline $11-29$ (insufficient) & $162(57.65 \%)$ \\
\hline$>30$ (sufficient) & $107(38.42 \%)$ \\
\hline
\end{tabular}

$174(61.92 \%)$ of the stroke had less than sufficient Vitamin D.

Table 4. Stroke subtypes and vascular territory

\begin{tabular}{|ll|}
\hline Areas of Brain & Frequency \\
\hline Ischemic Middle Cerebral Artery & $145(51.5 \%)$ \\
\hline Ischemic Anterior Cerebral Artery & $8(3 \%)$ \\
\hline Brain stem ischemia & $34(12.12 \%)$ \\
\hline Cerebellum ischemia & $12(3.07 \%)$ \\
\hline Thalamic infract & $12(4 \%)$ \\
\hline Multiple infract & $36(12.9 \%)$ \\
\hline Basal ganglia Bleed & $23(8.11 \%)$ \\
\hline Brainstem Bleed & $14(5.1 \%)$ \\
\hline
\end{tabular}

Middle cerebral artery (MCA) ischemia was noted in 51.5\% of patients and anterior cerebral artery (ACA) ischemia was noted in $3 \%$ of patients. Multiple infarcts were noted in $12.90 \%$ of patients.

\section{DISCUSSION}

Stroke is common neurological problems in Nepal. Cardio embolic stroke is the most common cause of stroke. Other causes are premature atherosclerosis, hematological, immunological disorders and migraine.

This study shows that smoking $(n=149)$ is commonest risk factor among stroke patients. Hypertension, low HDL, high triglyceride, diabetes mellitus are also common. Atrial fibrillation was found among 39 patients.

In this study, we found association between 25hydroxyvitamin $D$ deficiency and stroke. Similar results have been found from the western part of the world. . $^{4,5}$ 
We noted deficiency of 25-hyroxyvitamin $D$ in nearly $61.8 \%$ of stroke patients, which further divided into three categories insufficiency and deficient. A similar association of hypovitaminosis D with stroke was also found in north India. ${ }^{6}$

$1,25-\mathrm{OH} \mathrm{D}$ is the biologically active, hormonal form of vitamin $\mathrm{D}$; however, serum $25-\mathrm{OH} \mathrm{D}$ is regarded as the best indicator of vitamin $D$ status in individuals without kidney disease, because it is the substrate for the renal and non renal production of $1,25-\mathrm{OH} D$, has a longer biological half-life than $1,25-\mathrm{OH} \mathrm{D}$, and circulates in much higher concentrations. Serum $25-\mathrm{OH}$ D reflects the total production of vitamin $D$ from both endogenous and exogenous sources, including exposure to ultraviolet-B radiation and intake of various dietary forms.

In this analysis, $61.8 \%$ of cases had less than sufficient amount of Vitamin D. The mean Vitamin D level in the cases were $0-10$ (deficient) in $4.27 \%$ and insufficient in $57.65 \%$ of the stroke patients. This may have lead to the vascular events in the patients.

The mechanism of deficiency of vitamin $D$ and atherosclerosis is not fully understood. Li et al. observed that vitamin $D$ regulated blood pressure by suppressing the renin angiotensin system. ${ }^{7}$ Aihara et al. demonstrated vascular effects of vitamin $D$ with inhibition of thrombosis and reduction in arterial hypertension by vitamin $D$ deficiency. ${ }^{8,9}$

\section{REFERENCES}

1. World Health Organization. Global Health Estimates: Deaths by Cause, Age, Sex and Country, 2000-2012. Geneva, WHO, 2014.

2. Yusuf S, Rangarajan S, Teo K, Islam S, Li W, Liu L et al; PURE Investigators. Cardiovascular risk and events in 17 low-, middle-, and high-income countries. N Engl J Med. 2014; 371(9):818-27. doi:10.1056/ NEJMoa1311890.

3. Hansson GK, Libby P. The immune response in atherosclerosis: a double-edged sword. Nat RevImmunol. 2006;6:508-19.

4. Poole KE, Loveridge N, Barker PJ, Halsall D J, Rose C, Reeve J et al. Reduced vitamin D in acute stroke. Stroke. 2006; 37:243-5.

5. Sun Q, Pan A, Hu FB, Manson JE, Rexrode KM. 25-Hydroxyvi-tamin D levels and the risk of stroke: a prospective study and meta-analysis. Strok. 2012; 43:1470-77.

6. Chaudhari JR, Mridula KR, Alladi S, Anamika A, Umamahesh M, Balaraju B et al. Journal of Stroke. 2014;16(1):44-50.

7. Li YC, Kong J, Wei M, Chen ZF, Liu SQ, Cao LP. 1, 25-Dihy-droxyvitamin $D(3)$ is a negative endocrine regulator of the re-nin-angiotensin system. J Clin Invest. 2002; 110:229-38.
There was a study showed low 25-hydroxyvitamin D was significantly associated with increasing intimal media thickness and carotid plaques in individuals. ${ }^{10}$ Multiple level effect of Vitamin namely rennin angiotensin system, change in thrombotic state, arterial hypertension and intimal media changes may have increased risk of stroke.

An association between vitamin $D$ deficiency and atherogenic dyslipidemia has also been suggested. In a cross-sectional study that included 107811 patients, vitamin D was associated with a significant increase in total cholesterol and high-density lipoprotein cholesterol. ${ }^{11}$

Besides being a risk factor, stroke patients that $25(\mathrm{OH})$ D levels at hospital admission are associated with stroke severity, as well as with poor early functional outcome. ${ }^{12}$

We don't know the cause of deficiency of vitamin $D$ in Nepalese patient. The actual level of vitamin $D$ in general population of Nepal is yet to be identified.

\section{CONCLUSION}

Stroke is common neurological problems. Smoking, hypertension, diabetes mellitus, dyslipidemia, atrial fibrillation are major factors for associated with stroke. This small study also showed the relation of level of vitamin D with stroke. However systemic larger scale study needs to proof this association.

8. Aihara K, Azuma H, Akaike M, Ikeda Y, Yamashita M, Sudo T, et al. Disruption of nuclear vitamin $D$ receptor gene causes en-hanced thrombogenicity in mice. J BiolChem. 2004; 279:35798-802.

9. Watson KE, Abrolat ML, Malone LL, HoegJM, Doherty T, Detrano $\mathrm{R}$, et al. Active serum vitamin $\mathrm{D}$ levels are inversely correlated with coronary calcification. Circulation. 1997; 96: 1755-60.

10. Carrelli AL, Walker MD, Lowe H, McMahon DJ, Rundek T, Sacco RL, et al. Vitamin D deficiency is associated with sub-clinical carotid atherosclerosis: the Northern Manhattan study. Stroke. 2011;42: 2240-5.

11. Ponda MP, Huang $X$, Odeh MA, Breslow JL, kaufman HW . Vitamin D may not improve lipid levels: a serial clinical laboratory data study. Circulation. 2012; 126:270-7.

12. Daubail B, Jacquin A, GuillandJC, Hervieu M, OssebyGV, Rouaud O, et al. Serum 25-hydroxyvitamin D predicts severity and prognosis in stroke patients. Eur J Neurol. 2013;20:57-61. 